\title{
The Small Hydropower Plant Income Maximization Using Games Theory
}

\author{
Antans Sauhats, \\ Institute of Power Engineering \\ Riga Technical University, RTU \\ Riga, Latvia
}

\author{
Renata Varfolomejeva, Inga Umbrasko, Hasan Coban, \\ Institute of Power Engineering \\ Riga Technical University, RTU \\ Riga, Latvia
}

Received: January 24, 2021. Revised: March 12, 2021. Accepted: March 17, 2021. Published: March 23, 2021.

\begin{abstract}
This paper is devoted to the consideration of case of the use of small rivers energy, the current system of support relevant projects, its drawbacks and opportunities to remove them. Cooperative game theory approach is used for analysis of regime management of the small-scale hydro power plant (SHPP). Technical and economical aspects of the issue are observed. The obtained results demonstrate the validity of the cooperation for obtaining additional income.
\end{abstract}

Keywords-hydroelectric power generation, power generation planning, smart grids, games theory

\section{INTRODUCTION}

The rise in energy consumption, the growing dimensions of power systems, their degree of complication and significance, the increase in the prices of energy carriers, the influence of occasional factors and uncertainty - all of the aforementioned has sharpened a number of serious energy-related problems.

- Efficiency and availability of power supply. Unfortunately, the standards of living for different layers of population differ even in developed countries that are well provided with energy. Still larger are the differences in living standards between industrially developed countries and developing countries. Provision with energy resources is very inhomogeneous at various places of the world. As a result of this, one fourth of the world's population still have no access to electric energy sources and, consequently, to most of the benefits offered by modern civilization. The main reason for this is the energy price, which is inaccessible to the poorer layers of population. The growth in the energy prices hampers the development of industrial production and consequently limits the opportunities to solve many social and environmental problems.

- Reliability of power supply. Humanity has gradually got accustomed to conditions that are unthinkable without guaranteed energy supply and has adapted its way of living accordingly. Even in case of short-term power cuts, modern-day cities, industrial enterprises and transportation systems suffer damage and large-scale economic loss, emergency and catastrophe threats arise, possibly even with large casualties.
- Environmental impact. Energy production is practically impossible without influencing climate, the air and water basin, the natural sceneries and, as a result, the human living environment.

- Sustainability. This concept is linked to the limited amount of basic resources available to modern society. Although the amount of energy produced from renewable sources has increased considerably over the last decade, yet it is expected that almost $85 \%$ of the increase in the energy production amount will be related to an increase in the consumption of fossil fuel.

The acuity of the above problems has resulted in decisions on an international scale regarding the restructuring of power systems and the use of market conditions and mechanisms in the management of the development and operation of power systems. The power system is divided into a number of legally independent parts that compete with one another. Competition is the main factor that can ensure rational development of power systems. At competition conditions, it is inevitable that those companies that make correct, technically and economically substantiated decisions are more likely to survive.

Division of a system into a number of parts diminishes the dimensions of the objects to be managed. It seems that the models and algorithms for management and decision-making are simplified, yet at the same time, new problems emerge. To solve the problems described above are generally recognized two main ways:

1. Use of distributed generation. Preference is given to renewable energy sources.

2. Application of smart grid technologies, which uses information and communications technology to gather and act on information about the behaviors of suppliers and consumers, in an automated fashion.

Both ways have to be used to improve the efficiency, reliability, sustainability and to decrease environmental inpact of the production and distribution of electricity. The presence in the formulation of optimization task of four abovementioned problems generates the equal number of targets. Very often there are contradictions leading to facilitate some 
problems due to other. Proof of this is the use of renewable energy sources particularly small-scale hydropower plants, the implementation of which, in many cases is supported by legislation.

This paper is devoted to the consideration of case of the use of small rivers energy, the current system of support relevant projects, its drawbacks and opportunities to remove them.

\section{SUPPORTING SCHEMES OF RENEWABLE GENERATION}

Renewable energy in Latvia is promoted through different support schemes as in the other European countries. Favorable national feed-in support scheme for renewable generation in Latvia provided for a guaranteed purchase price, which is significantly higher than the electricity market price. Electricity Market Law prescribes, that a producer who generates electricity from renewable energy sources may acquire the right to sell the produced electricity to a public trader within the framework of the mandatory procurement at a guaranteed purchase price (feed-in tariff). Feed-in tariff depends on the kind of used energy resource and the installed capacity of the power plant.

A significant drawback of this mechanism is the producer revenues independence from market price fluctuations. Producers that sell electricity under a mandatory procurement, are not interested in harmonizing of their power generation schedule to the market price schedule, as produced energy has the same price at all time.

There are more than 200 medium and small rivers in Latvia and more than 140 small-scale hydropower plants $(5 \mathrm{MW}$ or less).

It would be possible to increase output by $10-20 \%$ by modernizing the production process. Total hydroenergy potential of small and middle size rivers is at least 4 times bigger.

\section{COALITION ESTABlishmENT AND SHAPLEY VALUE}

In game theory, the Shapley values a solution concept in cooperative game theory [11], [12]. To each cooperative game it assigns a unique distribution (among the players) of a total surplus generated by the coalition of all players. A coalition of players cooperates, and obtains a certain overall gain from that cooperation. The Shapley value provides one possible answer to this question.

The main idea of the paper is based on coalition creation between SHPPs and public trader. In that case, as it is shown below, appears:

- the ability of getting the additional income;

- the problem of equitable distribution of income among members of the coalition [11],[12],[13].

This problem can be solved by using the methods of cooperative games theory.

A coalition does not require the repeal of the existing legislation on support of renewable energy sources. At the same time the results of this work can be considered as an argument for amendments of legislation in the future.

To formalize this situation, we use the notion of a coalitional game: we start out with a set $N$ (of $n$ players) and a function $v: 2^{N} \rightarrow \mathbb{R}_{\text {with }} v(\varnothing)=0$, where $\varnothing$ denotes the empty set. The function $v$ that maps subsets of players to reals is called a characteristic function.

The function $v$ has the following meaning: if $S$ is a coalition of players, then $v(S)$, called the worth of coalition $S$, describes the total expected sum of payoffs the members of $S$ can obtain by cooperation.

The Shapley value is one way to distribute the total gains to the players, assuming that they all collaborate. According to the Shapley value, the amount that player $i$ gets given a coalitional game $(v, N)$ is

$$
\phi_{i}(v)=\sum_{S \subseteq N \backslash\{i\}} \frac{|S| !(n-|S|-1) !}{n !}(v(S \cup\{i\})-v(S)),
$$

where $n$ is the total number of players and the sum extends over all subsets $S$ of $N$ not containing player $i$. The formula can be interpreted as follows: imagine the coalition being formed one actor at a time, with each actor demanding their contribution $v(S \cup\{i\})-v(S)$ as a fair compensation, and then for each actor take the average of this contribution over the possible different permutations in which the coalition can be formed.

In case if coalition is formed by all participants and coalition is known, it is not necessary to determine mathematical expectation of different coalition's variants and the expression (1) can be written as [18]:

$$
\phi_{i}(v)=\frac{1}{|N| !} \sum_{R}\left[v\left(P_{i}^{R} \cup\{i\}\right)-v\left(P_{i}^{R}\right)\right]
$$

where the sum ranges over all $|N|$ ! orders $\mathbb{R}$ of the players and $P_{i}^{R}$ is the set of players in $N$ which precede $i$ in the order $\mathbb{R}$.

Shapley allocation is inherent significant drawback because the volume of calculations in determining the Shapley value , in common case, catastrophically increases with increasing number of players [11]. Discussed below task really is formulated for a large number of players, but the specific features of their unification into a coalition lead to the ultimate simplification of distribution calculations Shapley.

\section{SPECIFIC FEATURES OF SHPP UNIFICATION INTO A COALITION}

Consider a simplified description of a power system business. We have an owner (power system operator) o, which does not produce energy but provides regimes planning and operation, meaning that without him no gains can be obtained. Then we have $k$ SHPP $w_{1}, \ldots, w_{k}$, each $I$ of whom contributes an 
amount sip to the total profit. The contribution of each power plant is only possible in a coalition with the operator and is independent of the participation or non-participation of other hydropower plants in the coalition. So $N=\left\{0, w_{1}, \ldots, w_{k}\right\}$ and $v(S)=0$ if $\quad 0$ is not a member of $S$ and $v(S)=\operatorname{sum}\left(s^{1} p+s^{2} p+\ldots+s^{k} p\right)$ if $S$ contains the owner and $k$ SHPP. The coalition between the SHPP without an operator is not possible because it does not give additional profit. Computing the Shapley value for this coalition game leads to a value of sum $\left(s^{1} p+s^{2} p+\ldots+s^{k} p\right) / 2$ for the owner and $s^{i} p / 2$ for each worker.

\section{SHPP REGIME OPTIMIZATION}

The idea of regulation process is that in some periods of time SHPP works with water consumption excessing inflow by consuming water from the reservoir before dam and at other periods of time SHPP uses less water than inflow and fill up the reservoir before dam.

The time interval from the beginning of one period of reservoir drawdown to the next drawdown period after its filling up is called a regulation cycle.

The small capacity of water reservoir (without opportunity of long regulation) does not allow using regular changes in seasonal water inflow. According to this condition planned drawdown and filling up of water reservoir with small capacity can be made only in connection with regular changes of the total electrical load in the power system, which has the daily and weekly periodicity.

The change of water pressure on SHPP is caused by the change of water level in upstream and downstream. This is due to the water use through the turbines of SHPP. Hence, the change of the water level should be restricted by $H_{\max }$ from the top and by $H_{\min }$ from the bottom, i.e.

$$
H_{\text {min }} \leq H \leq H_{\max }
$$

The capacity of hydro unit is determined with the expression:

$$
P_{S H P P_{j}}=9,81 \cdot \eta_{H A} \cdot Q_{j} \cdot H_{j},
$$

where $P_{S H P P}$ - SHPP capacity, $k W ; Q$ - water flow through the turbine, $\mathrm{m}^{3} / \mathrm{sec}$.; $H$ - difference between water levels at the SHPP, $m ; \eta_{H A}$ - efficiency factor of hydro unit in relative units: $\eta_{H A}=\eta_{\text {turb }} \cdot \eta_{G}$, where $\eta_{\text {turb }}$ - turbine efficiency factor in relative units; $\eta_{G}$ - generator efficiency factor in relative units [4],[5],[6],[7], [17].

The mathematical task of SHPP maximal income deriving in market conditions can be formulated as follows. It is required to determine the SHPP operating schedule by providing maximum income for the regulation cycle $T$.

$$
I\left(P_{1}, P_{2}, \ldots, P_{j}\right)=\sum_{j=1}^{J} I_{j}\left(c_{j}, P_{j}\right) \rightarrow \max ,
$$

under the condition (3) and condition of use of the set amount of water $W_{J}$ in water reservoir

$$
\sum_{j=1}^{J} Q_{j} \cdot \Delta t_{j}=W_{J}
$$

where $I_{j}\left(c_{j}, P_{j}\right)$ - income from sale of electricity, that is produced on SHPP during the time interval $\Delta t_{j}$ by known market price $c_{j}, € ; T-$ the regulation cycle duration: $T=\sum_{j=1}^{J} \Delta t_{j} ; Q_{j}$ - the water flow through the SHPP flap during the time interval, $\mathrm{m}^{3} / \mathrm{sec} ; W_{J}$ - the set amount of water that could be passed through the SHPP flap per regulation cycle (day, week and etc.).

The time interval equals to $\Delta t_{j}=1$ hour at the daily regulation cycle of SHPP. The power generation on SHPP during to the $\mathrm{j}$-th interval $\Delta t_{j}$ is defined as: $P_{j} \cdot \Delta t_{j}$. At the known natural inflow (the natural inflow of the river, due to which the reservoir is filled up) $Q_{\text {flow }}$, the used water flow in each time interval of regulation is determined by value $Q_{j}$ that depends of the usage of water reservoir capacity $\left(m^{3}\right)$ [5], [6].

The water pressure in the dam at the SHPP in $j$-th time interval varies depending on the amount of water worked through the turbine

$$
H_{j}=H_{j-1} \pm \Delta H_{j}
$$

where $H_{j-1}$ - water pressure at $\Delta t_{j-1}$ time interval, m; $\Delta H_{j}$ water pressure change depending on worked out water amount $\mathrm{m}^{3}$ (or $\Delta h_{j}=$ var, $\mathrm{m}$ ) and on natural water inflow amount of river $Q_{\text {piepl. }}=$ const, $\mathrm{m}^{3}$ (or express from the water level increase of dam surface $\Delta h_{\text {piepl }}=$ const, $\left.\mathrm{m}\right)$.

The operability of developed algorithm is illustrated on the example of two SHPP regime optimizations.

1. The first SHPP main data which allows its regulation is given: the maximal level of the water reservoir $-8,2 \mathrm{~m}$; nominal capacity $-300 \mathrm{~kW}$; the year average inflow into the water reservoir $-2,4 \mathrm{~m} 3 / \mathrm{sec}$. Due to the regulations of the environmental protection in Latvia the minimal level of the water in the SHPP reservoir should not be less than 7,9 $\mathrm{m}$ [2], [3].

2. The second SHPP main data which allows its regulation is given: the maximal level of the water reservoir $-8,3 \mathrm{~m}$; nominal capacity $-500 \mathrm{~kW}$; the year average inflow into the water reservoir $-3,0 \mathrm{~m} 3 / \mathrm{sec}$. Due to the regulations of the 
environmental protection in Latvia the minimal level of the water in the SHPP reservoir should not be less than $8,0 \mathrm{~m}$.

The SHPP income is found for regime regulation considering water inflow and water level restrictions - SHPP optimizes its working regime.

The optimization was made for the summary income (objective function) for whole day period ( 24 hours). The results have been found by using nonlinear programming generalized reduced gradient method (GRG) [9]. Genetic algorithms (evolutionary method) and dynamic programming (DP) also can be used in that task. The GRG method usage can provide more accurate result than DP, because GRG method does not depend from the discretization, i.e. water level step value. Superiority of GRG method over DP method in such task is considered in [14]. Use of genetic algorithm is discussed in [15], [16].

In respect that first 20 years from the date of taking of the decision to grant the SHPP the right to sell the produced electricity within the scope of mandatory procurement, SHPP sells electricity at feed-in tariff, so it is actual to optimize the power station operation regime at a constant price value $(0,18$ $€ / \mathrm{kWh}$.) [8]. In this case, SHPP increases its income by maximizing power production (Fig.2, Fig.4). The water level (accumulation and drawdown of water) changes charts is presented at Fig.1 and Fig.3.

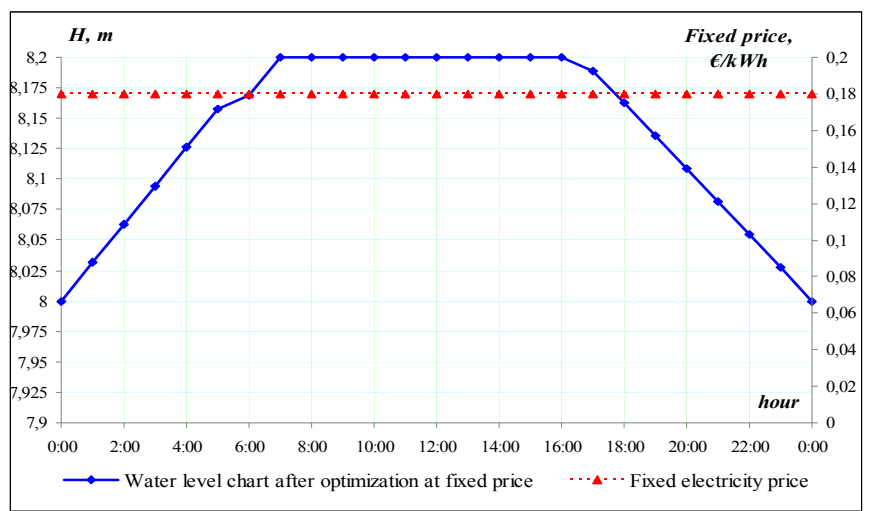

Fig. 1. Water level chart for the first SHPP, in optimization is used fixed price

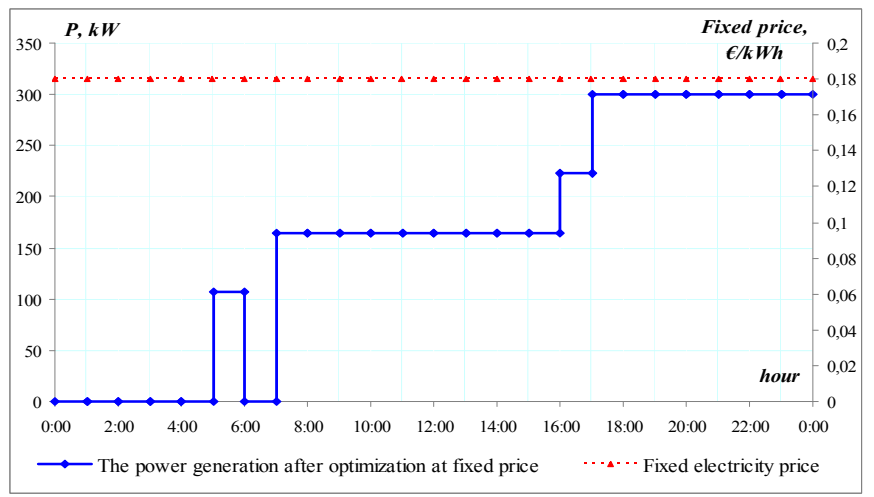

Fig. 2. The price and generated power graphs for the first SHPP, in optimization is used fixed price

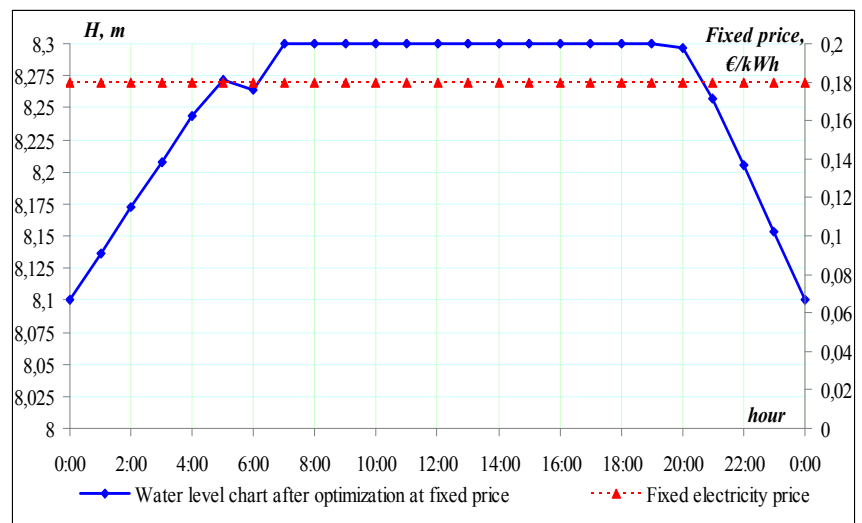

Fig. 3. Water level chart for the second SHPP, in optimization is used fixed price

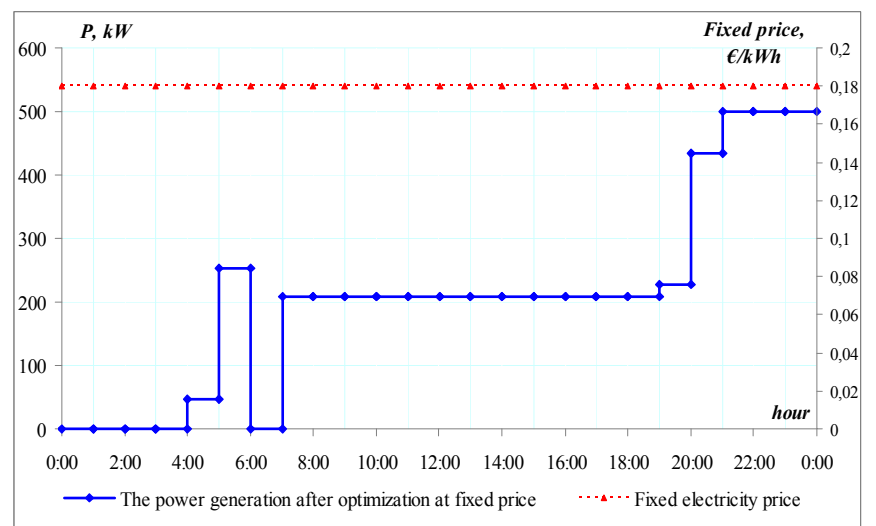

Fig. 4. The price and generated power graphs for the second SHPP, in optimization is used fixed price

The income at feed in tariff (from optimization considering the natural inflow and the ability to store up water (Fig.1.Fig.4.)) for the first SHPP is about 703,24 $€$, but for the second SHPP is $891,415 €$.

The public trader (AS "Latvenergo") buys and sells electricity in the Nord Pool Spot [1] exchange stock and should buy all electricity produced under mandatory procurement. As previously mentioned, SHPPs are not interested in harmonizing of their power generation schedule to the market price schedule, as produced energy has the same price at all time. They produce electricity at their own discretion and can work at full capacity in the hours with minimal load that adversely affect public trader. That is why it is important to optimize regime of SHPP considering price changes in the market (for example Nord Pool Spot).

Such approach can lead to additional income for the public trader. To motivate SHPPs to work according to the market price schedule public trader share this additional income with SHPPs. Surely, SHPPs sell produced electricity to system operator at the feed-in tariff.

The obtained results show (Fig.5-Fig.8) that when regime is optimized by market price SHPP accumulates water in the case when the electricity price at the market is relatively low and 
exhaust water at the high price level, considering restriction (3) and the maximum power restriction.

The income at market price (from optimization considering that the SHPP produces power in dependence of the market price, but sell produced electricity at fixed tariff Fig.5.-Fig.8.) for the first SHPP is about $692,94 €$, but for the second SHPP is $875,757 €$.

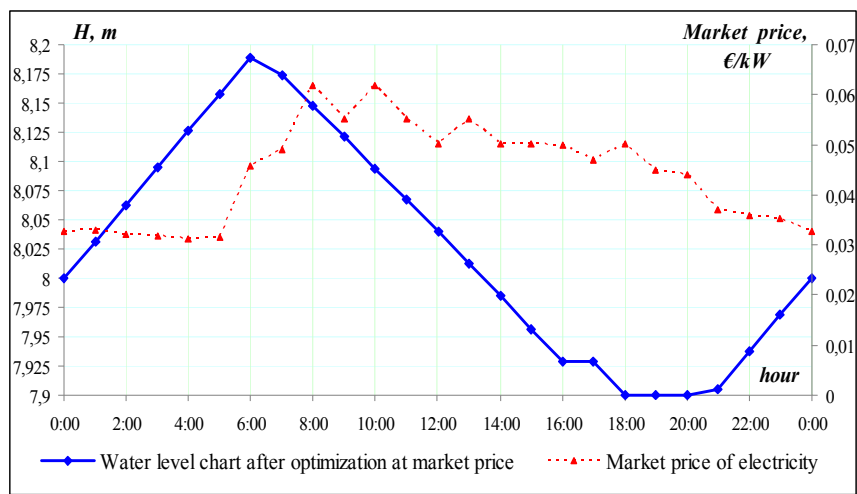

Fig. 5. Water level chart for the first SHPP, in optimization is used market price

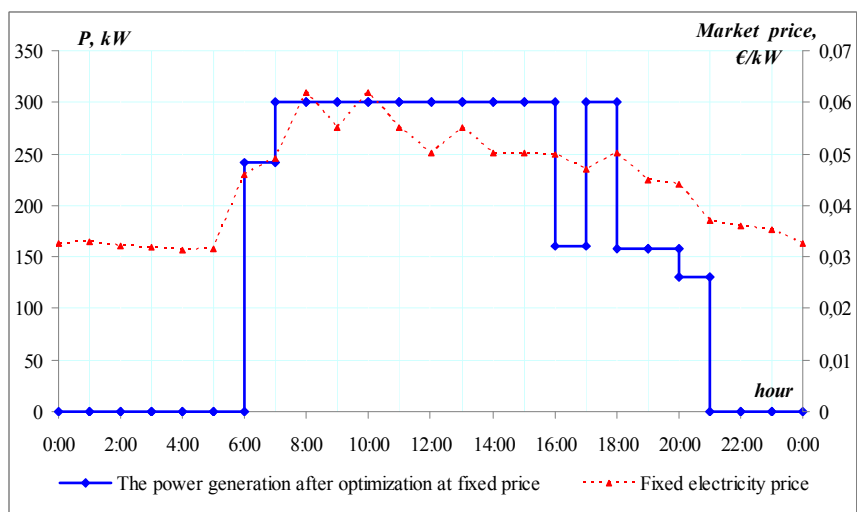

Fig. 6. The price and generated power graphs for the first SHPP, in optimization is used market price

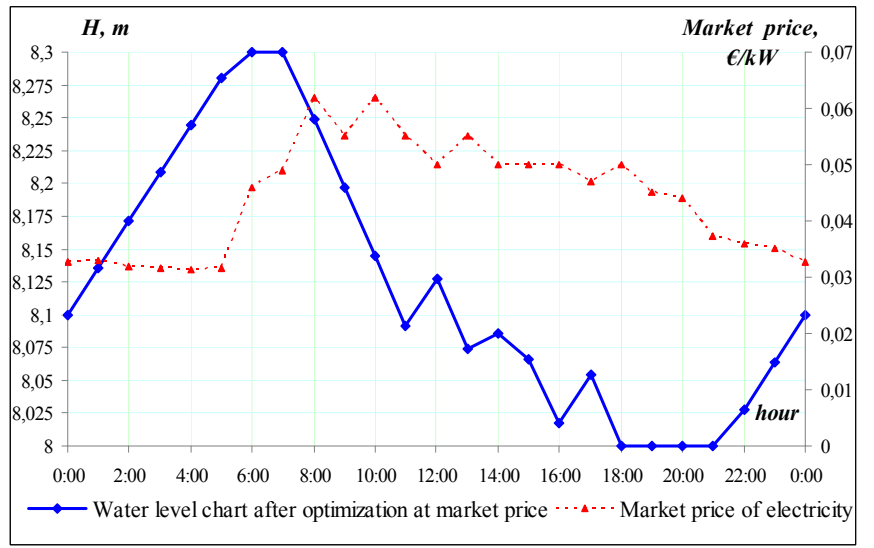

Fig. 7. Water level chart for the second SHPP, in optimization is used market price

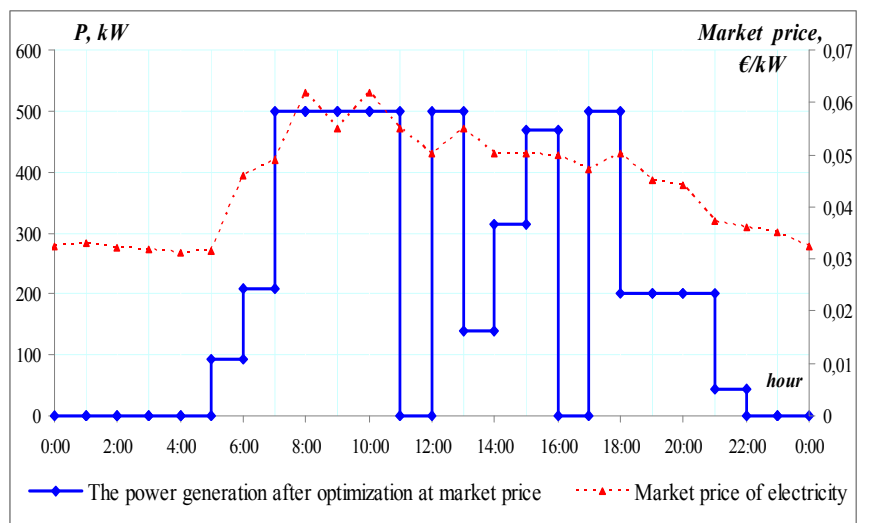

Fig. 8. The price and generated power graphs for the second SHPP, in optimization is used market price

So, how to distribute all additional income if is made coalition of market participants.

The public trader (player 3) buys electricity from SHPPs, and if it is not in coalition with them $v(3)=0 €$. If SHPPs are not in coalition with public trader, they get the income from selling electricity by feed in tariff: the first SHPP (player 1) $v(1)=703.24 €$, and the second SHPP (player 2)$v(2)=891.42 €$. If there is the coalition of two SHPPs, the summary income is $v(1,2)=1594,65 €$. The coalition of the first SHPP with the public trader brings an income $v(1,3)=713,43 €$, accordingly, the coalition of the second SHPP with the public trader brings an income $v(2,3)=910,51$ $€$. The coalition of all three companies would provide the income $v(1,2,3)=1623,936 €$. In that way the gain of all coalitions can be determined as:

$$
v(S)=\left\{\begin{array}{ll}
703.24, & S=\{1\} \\
891.42, & S=\{2\} \\
0, & S=\{3\} \\
1594.65, & S=\{1 ; 2\} \\
713.43, & S=\{1 ; 3\} \\
910.51, & S=\{2 ; 3\} \\
1623.936 & S=\{1 ; 2 ; 3\}
\end{array} .\right.
$$

Co-operative game $(v, N)$ is called relevant if

$$
\sum_{i \in N} v(i)<v(N)
$$

The division of game $(v, N)$ is a vector $x=\left(x_{1}, x_{2}, x_{3}\right)^{T}$, which meets following conditions:

$\sum_{i \in N} x_{i}=v(N)$ (condition of co-operative expediency),

$x_{i} \geq v(i), i \in N$ (condition of individual expediency).

In that game the division will be vectors $x=\left(x_{1}, x_{2}, x_{3}\right)^{T}$, which meets following conditions: 


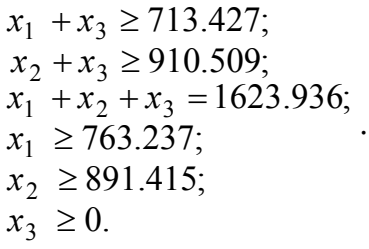

For the insignificant value of $n$ the calculation process of the Shapley value is easy to describe in table form.

TABLE I. PARTICIPANT INCOME DETERMINATION

\begin{tabular}{|l|c|c|c|}
\hline \multirow{2}{*}{ Variations } & \multicolumn{3}{|c|}{ The Participants Income, $\boldsymbol{€}$} \\
\cline { 2 - 4 } & $\mathbf{1}$ & $\mathbf{2}$ & $\mathbf{3}$ \\
\hline $1,2,3$ & 703,237 & 891,415 & 29,283 \\
\hline $1,3,2$ & 703,237 & 910,509 & 10,189 \\
\hline $2,1,3$ & 703,237 & 891,415 & 29,283 \\
\hline $2,3,1$ & 713,427 & 891,415 & 19,094 \\
\hline $3,1,2$ & 713,427 & 910,509 & 0 \\
\hline $3,2,1$ & 713,427 & 910,509 & 0 \\
\hline $\begin{array}{c}\text { Average } \\
\text { income }\end{array}$ & 708,332 & 900,962 & 14,642 \\
\hline
\end{tabular}

The result (Shapley vector) is given in the last row of the Table 1:

$$
x=\left(x_{1}, x_{2}, x_{3}\right)^{T}=(708.33,900.96,14.64)^{T} .
$$

\section{CONCLUSION}

The maximal income of SHPP can be obtained in the conduct of its regime depending on schedule of electricity price change.

In terms of operation a SHPP in a period of low prices, it can be shut down, accumulating water. It is required to consider restrictions on the natural water flow on small rivers and possible amount of water that may be consumed by a SHPP during the day.

The example of this paper shows that participants could get the additional income from cooperation in the game.

\section{REFERENCES}

[1] Nord Pool Spot home page: http://www.nordpoolspot.com/Marketdata1/Elspot/Area-Prices/ALL1/Hourly/

[2] Small Hydropower Association home page: http://www.mhea.lv/component/content/article/62/73-brzes-dzirnavuhes.html/ (in Latvian)

[3] Latvijas Vides, Ģeologijas un Meteorologijas Centrs home page: http://www.meteo.lv/en/ (in Latvian)

[4] V.M.Gornshteyn, The most profitable operating regimes of hydro power plant in the power systems, Moscow: Gosenergoizdat, 1959, p. 248. (in Russian)
[5] J. Gerhards, A.Mahnitko, The power system regime optimization, Riga: Riga Technical University, 2005, pp. 249. (in Latvian)

[6] L.P. Mikhailov, B.N. Feldman, T.K. Markanova and others, Small Hydroenergetic, Moscow: Gosenergoizdat, 1989, p. 184. (in Russian)

[7] J.Balodis, Small hydropower plants, Riga: Latvian State Publishing, 1951, pp.155. (in Latvian)

[8] Y Cabinet Regulation No. 262 of 16 March 2010. Regulations Regarding the Production of Electricity Using Renewable Energy Resources and the Procedures for the Determination of the Price.

[9] Varfolomejeva, R., Umbraško, I., Mahņitko, A. The Small Hydropower Plant Operating Regime Optimization by the Income Maximization. No: Powertech Grenoble 2013: Powertech Grenoble 2013, Grenoble: 2013, pp.1.-6.

[10] R. Tiainen, T. Lindh, J. Ahola, M. Niemelä, V. Särkimäki, Energy pricebased control strategy of a small-scale head-dependent, hydroelectric power plant, in: International Conference on Renewable Energies and Power Quality, 2008.

[11] E. Faria, L.A. Barroso, R. Kelman, S. Granville and M.V. Pereira. Allocation of Firm-Energy rights among hydro plants: An AumannShapley approach. In Power Systems, IEEE Transactions on, 24(2): 541551, 2009.

[12] M. Zima-Bockarjova, J. Matevosyan, M. Zima, and L. Sdoder, "Sharing of Profit From Coordinated Operation Planning and Bidding of Hydro and Wind Power," in IEEE Transactions on Power Systems, vol.25, no.3, pp.1663-1673,August 2010, doi: 10.1109/ TPWRS.2010.2040636

[13] M. Bockarjova, M. Zima, and G. Andersson. On allocation of the transmission network losses using game theory. In Electricity Market, 2008. EEM 2008. 5th International Conference on European, pp. 1-6, 2008 .

[14] R.Varfolomejeva, I. Umbrasko, A. Mahnitko. Algorithm of Intellectual Control System Operation of Small Hydropower Plant.// Proceedings of 12th International Conference on Invironment and Electrical Engineering EEEIC 2013. Wroclaw, Poland, May, 2013. 414-418.pp.

[15] P. Sangsarawut, A. Oonsiivilai, T. Kulworawanichpong. Optimal Reactive Power Planning of Doubly Fed Induction Generators Using Genetic Algorithms.// Proceedings of $5^{\text {th }}$ International Conference on Energy and Environment. IASME/WSEAS. UK, 2010, 278.- 282.pp.

[16] Sepehr Sanaye, Amir Mohammadi Nasab. Modeling and optimization of a natural gas pressure reduction station to produce electricity using genetic algorithm. .// Proceedings of $6^{\text {th }}$ International Conference on Energy, Environment, Sustainable Development and Landscaping. WSEAS. Romania, 2010, 62.- 70.pp.

[17] M. Grigoriu, M.Popescu. Hydropower Preventive Monitoring Action Plan. .// Proceedings of $5^{\text {th }}$ International Conference on Energy and Environment. IASME/WSEAS. UK, 2010, 265.- 270.pp.

[18] Y. Narahari. Lecture Notes, Game Theory. Cooperative game theory. Department of Computer Science and Automation. India, 2009.-1.12.pp.

\section{Creative Commons Attribution License 4.0 (Attribution 4.0 International, CC BY 4.0)}

This article is published under the terms of the Creative Commons Attribution License 4.0 https://creativecommons.org/licenses/by/4.0/deed.en US 